\title{
Release of organic nitrogen compounds from kerogen via catalytic hydropyrolysis
}

\section{B. Bennett* and G. D. Love}

Fossil Fuels and Environmental Geochemistry (Postgraduate Institute): NRG, Drummond

Building, The University, Newcastle upon Tyne, UK NE17RU.

E-mail: barry.bennett@ncl.ac.uk

Received 26th October 2000, Accepted 1st December 2000

Published on the Web 7th December 2000

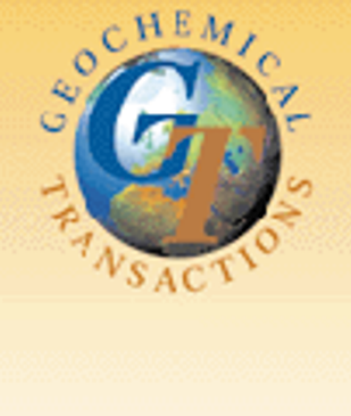

Article

High hydrogen pressure pyrolysis (hydropyrolysis) was performed on samples of solvent extracted Kimmeridge Clay Formation source rock with a maturity equivalent to $c a .0 .35 \%$ vitrinite reflectance. We describe the types and distributions of organic nitrogen compounds in the pyrolysis products (hydropyrolysates) using GC-

MS. Compounds identified included alkyl-substituted indoles, carbazoles, benzocarbazoles, quinolines and benzoquinolines. The distributions of the isomers of methylcarbazoles, $\mathrm{C}_{2}$-alkylcarbazoles and benzocarbazoles in the hydropyrolysates were compared to a typical North Sea oil. The hydropyrolysates compared to the North Sea oil, showed increased contributions from alkylcarbazole isomers where the nitrogen group is "exposed" (no alkyl substituents adjacent to the nitrogen functionality) and appreciable levels of benzo $[b]$ carbazole relative to benzo $[a]$ - and benzo[c]carbazoles. Hydropyrolysis is found to be an ideal technique for liberating appreciable quantities of heterocyclic organic nitrogen compounds from geomacromolecules. The products released from the immature Kimmeridge Clay are thought to represent a potential source of nitrogen compounds in the bound phase (kerogen) able to contribute to the free bitumen phase during catagenesis.

\section{Introduction}

Hydropyrolysis refers to pyrolysis assisted by high hydrogen gas pressures ( $>10 \mathrm{MPa}$ ). In an open-system, fixed-bed reactor configuration with an active catalyst dispersed in the sample, overall conversions are typically greater than $90 \%$ for petroleum source rocks with high selectivities to soluble tar products. ${ }^{1,2}$ Hydropyrolysis was first developed and applied as an analytical pyrolysis method for liberating covalently-bound hydrocarbon structures from kerogen by Love et $a l^{3}$ Subsequent work has demonstrated the unique ability of the hydropyrolysis procedure to release higher yields of aliphatic biomarker hydrocarbons (including $n$-hydrocarbons, hopanes, steranes and methyl steranes) from immature kerogens in comparison with solvent extraction and conventional pyrolysis methods ${ }^{4-8}$ with excellent retention of product structural and stereochemical features. A more recent study has shown that immature biomarker hydrocarbons can also be released from oil and source rock asphaltenes and that the biomarker profiles produced from hydropyrolysis are useful for source correlation purposes. ${ }^{9}$

Until now, hydropyrolysis applications in organic geochemistry have exclusively utilised molecular constituents contained within hydrocarbon fractions (aliphatics and aromatics) to provide biogeochemical information. This study represents the first attempt at determining product distributions and potential uses of organic nitrogen-containing constituents of hydropyrolysates. While organic sulfur and oxygen functionalities are susceptible to reductive removal under hydropyrolysis conditions, organic nitrogen compounds (with the exception of amides) are much more inert. Appreciable nitrogen removal from heterocyclic aromatic compounds requires much more vigorous hydro-treatment than the experimental conditions encountered in our hydropyrolysis regime can provide. ${ }^{10}$ Hydropyrolysis is, therefore, ideal for liberating heterocyclic organic nitrogen compounds from geomacromolecules and the products formed should be highly representative of the molecular structures which are actually covalently-bound within the host macromolecular matrix.
Organic nitrogen compounds have been studied in shale oils, ${ }^{11}$ source rock extracts, ${ }^{12}$ crude oils ${ }^{13}$ and rock pyrolysates. ${ }^{14}$ Most organic nitrogen compounds in crude oils are present as alkylated heterocycles with a predominance of the neutral pyrrolic structures over the pyridinic forms. ${ }^{15}$ Pyrrolic compounds according to Richter et al. ${ }^{15}$ are classified into the non-basic (neutral) nitrogen groups, whereas pyridinic compounds belong to the basic nitrogen group. The pyrrolic type structures include the pyrroles (I), indoles (II) and carbazoles (III) (see Scheme 1). The pyrroles and indoles are susceptible to alteration and occur only as minor constituents of petroleum $^{16,17}$ and may contribute to sediment formation in middle distillates and fuel oils. ${ }^{18}$ The carbazoles and benzocarbazoles (benzo $[a]-(\mathbf{I V})$, benzo $[b]-(\mathbf{V})$ and benzo $[c]$ carbazoles (IV)) have been extensively studied in source rocks and petroleum. ${ }^{19-21}$ The pyridinic forms of nitrogen compounds in petroleum and shale oils are commonly represented by pyridine (VII), quinoline (VIII) and benzoquinolines (IX, X, XI, XII). The alkylquinolines and alkylbenzoquinolines represent the most intensively studied aromatic basic nitrogen compounds in fuels and sediments. ${ }^{12,13,22,23}$ Quinoline and other basic nitrogen compounds are abundant in oil shale retorts and pyrolysates but show a more limited occurrence in oils. ${ }^{24}$

The distributions of organic nitrogen compounds in source rocks and related crude oils have shown large and systematic variations due to fractionation effects associated with the migration process. ${ }^{12,19,20,23}$ Both Yamamoto ${ }^{23}$ and Li et al. ${ }^{19}$ described changes amongst nitrogen compound isomers based on steric effects favouring the preferential accumulation of nitrogen shielded (alkyl group adjacent to the nitrogen group) isomers relative to nitrogen exposed (no alkyl substituents at position $\mathrm{C}-1$ and $\mathrm{C}-8$ of carbazole III) isomers during petroleum migration. However, it is difficult to distinguish the effects of primary migration, expulsion and secondary migration in the carrier bed upon the nitrogen compound distributions by comparing source rocks and crude oils.

During this study we aim to use high hydrogen pressure pyrolysis to release organic nitrogen compounds from immature kerogen and identify the nitrogen compound types 
<smiles>c1cc[nH]c1</smiles><smiles>c1ccc2[nH]ccc2c1</smiles><smiles>c1ccc2c(c1)[nH]c1ccccc12</smiles><smiles>c1ccc2c(c1)ccc1c3ccccc3[nH]c21</smiles><smiles>c1ccc2cc3c(cc2c1)[nH]c1ccccc13</smiles><smiles>c1ccc2c(c1)[nH]c1ccccc12</smiles><smiles></smiles><smiles>c1ccc2c(c1)ccc1ncccc12</smiles><smiles>c1ccc2c(c1)cnc1ccccc12</smiles>

Scheme 1 Structures of pyrrolic and pyridinic nitrogen compounds.

and distributions that may be present in source rock organic matter prior to catagenetic release from the bound phase as primary migration, petroleum expulsion and secondary migration. We report the preliminary results as part of our continuing studies on the origin and fate of organic nitrogen compounds in the geosphere.

\section{Experimental}

\section{Catalytic hydropyrolysis}

Two samples of Kimmeridge Clay Formation (KCF) shales were obtained from the type location in Kimmeridge Bay (Dorset, UK). General sample information is given in Table 1. The samples were pre-extracted via Soxhlet using azeotrope dichloromethane $\mathrm{CH}_{2} \mathrm{Cl}_{2}$-methanol $(93: 7 \mathrm{v} / \mathrm{v})$. The solventextracted sediment residues were impregnated with an aqueous solution of ammonium dioxydithiomolybdate $\left[\left(\mathrm{NH}_{4}\right)_{2} \mathrm{MoO}_{2} \mathrm{~S}_{2}\right]$ to give a nominal loading of molybdenum of $1 \mathrm{wt} . \%$. The apparatus and basic procedures used for temperature-programmed hydropyrolysis have been described in detail elsewhere. ${ }^{3}$ Briefly, samples were mixed with acidwashed sand $(1: 5 \mathrm{w} / \mathrm{w})$ and heated in a stainless steel reactor tube from 150 to $520^{\circ} \mathrm{C}$ at $8^{\circ} \mathrm{C} \mathrm{min}^{-1}$ using a hydrogen pressure of $15.0 \mathrm{MPa}$. A hydrogen flow of $10 \mathrm{dm}^{3} \mathrm{~min}^{-1}$, measured at ambient temperature and pressure, through the reactor ensured that the overall conversion was not limited by mass transfer in the sample bed ${ }^{2}$ and that volatiles escaped quickly. The tar product (hydropyrolysate) was collected in a trap cooled with dry-ice and recovered in $\mathrm{CH}_{2} \mathrm{Cl}_{2}$-methanol $(93: 7 \mathrm{v} / \mathrm{v})$ for subsequent fractionation.

\section{Recovery of nitrogen compounds by solid phase extraction}

The organic nitrogen compounds were isolated from the hydropyrolysates (KC3 and KC4) and KCF-derived North Sea oil (Miller Field), using a modified version of the solid phase extraction (SPE) methods described in Bennett et al. ${ }^{25}$ Following complete removal of $\mathrm{CH}_{2} \mathrm{Cl}_{2}$ and methanol, the hydropyrolysate residue was dissolved in $n$-hexane (agitated via sonication) and then transferred to a C18 non-endcapped SPE cartridge (Jones Chromatography, UK). The oil sample may be applied directly onto the SPE cartridge. Firstly, the aliphatic and aromatic hydrocarbon fraction is eluted with $n$-hexane $(5 \mathrm{ml})$. The polar non-hydrocarbon fraction containing organic nitrogen compounds was recovered in $\mathrm{CH}_{2} \mathrm{Cl}_{2}(5 \mathrm{ml})$ and then the solvent reduced to minimum volume under nitrogen gas prior to GC-MS analysis.

\section{Gas chromatography-mass spectrometry}

The organic nitrogen compounds were analysed on a fused silica capillary column (HP-5; 95\%/5\%, methyl/phenyl silicone; dimensions, $30 \mathrm{~m} \times 0.32 \mathrm{~mm}$ id, $0.25 \mu \mathrm{m}$ film thickness (Hewlett-Packard)). The GC oven temperature program was $40{ }^{\circ} \mathrm{C}$ held for $2 \mathrm{~min}$, then $4{ }^{\circ} \mathrm{C} \mathrm{min}{ }^{-1}$ to $300^{\circ} \mathrm{C}$ and held at the final temperature for $20 \mathrm{~min}$.

Mass spectral characterisation of the organic nitrogen compounds was carried out using combined gas chromatography-mass spectrometry (GC-MS) on a Hewlett-Packard 5890 GC (using splitless injection) interfaced to a HP 5970B quadrupole mass selective detector (electron input energy $70 \mathrm{eV}$, source temperature $250^{\circ} \mathrm{C}$ ).

Compound identification was based on relative retention times, comparison of mass spectra with published mass spectra and, where standard compounds were available, by cochromatography.

\section{Quantification of organic nitrogen compounds}

A standard stock solution of $N$-phenylcarbazole was prepared in $\mathrm{CH}_{2} \mathrm{Cl}_{2}$. The standard was added to the organic nitrogen compound-enriched fraction prior to GC-MS analysis. Peak area integration during GC-MS analysis was by MASS LAB. The relative response factor (RRF) between $N$ phenylcarbazole and related compounds was assumed to be 1 .

\section{Results and discussion}

General sample details of the two Kimmeridge Clay Formation shales employed for this study are shown in Table 1. The total organic carbon content and carbonate content identify differences in gross composition. With reference to vitrinite reflectance $\left(c a .0 .35 \% \quad R_{\mathrm{o}}\right)$ the samples were assigned as "immature". The polar non-hydrocarbon fraction isolated from the hydropyrolysates was found to be enriched in aromatic nitrogen compounds of the pyrrolic (indoles, carbazoles and benzocarbazoles) and pyridinic (quinolines and benzoquinolines) structural types. The characterisation and determination of pyrrolic and pyridinic nitrogen compounds are described below.

\section{Alkylcarbazoles}

The partial mass chromatograms representing the distributions of methylcarbazoles and $\mathrm{C}_{2}$-alkylcarbazoles isolated from the

Table 1 General sample details for 2 Kimmeridge Clay Formation samples

\begin{tabular}{|c|c|c|c|c|c|c|c|c|c|}
\hline Code & Sample & Total organic carbon & [CaCO3] (\%) & TS $(\%)$ & So & $\mathrm{S} 1$ & $\mathrm{~S} 2$ & Tmax & HI \\
\hline $\mathrm{KC} 3$ & Oil shale & 28.1 & 35.0 & 5.3 & 0.02 & 3.6 & 178 & 428 & 632 \\
\hline $\mathrm{KC} 4$ & Bituminous mud & 11.6 & 1.7 & 4.5 & 0.02 & 1.5 & 66 & 428 & 571 \\
\hline
\end{tabular}




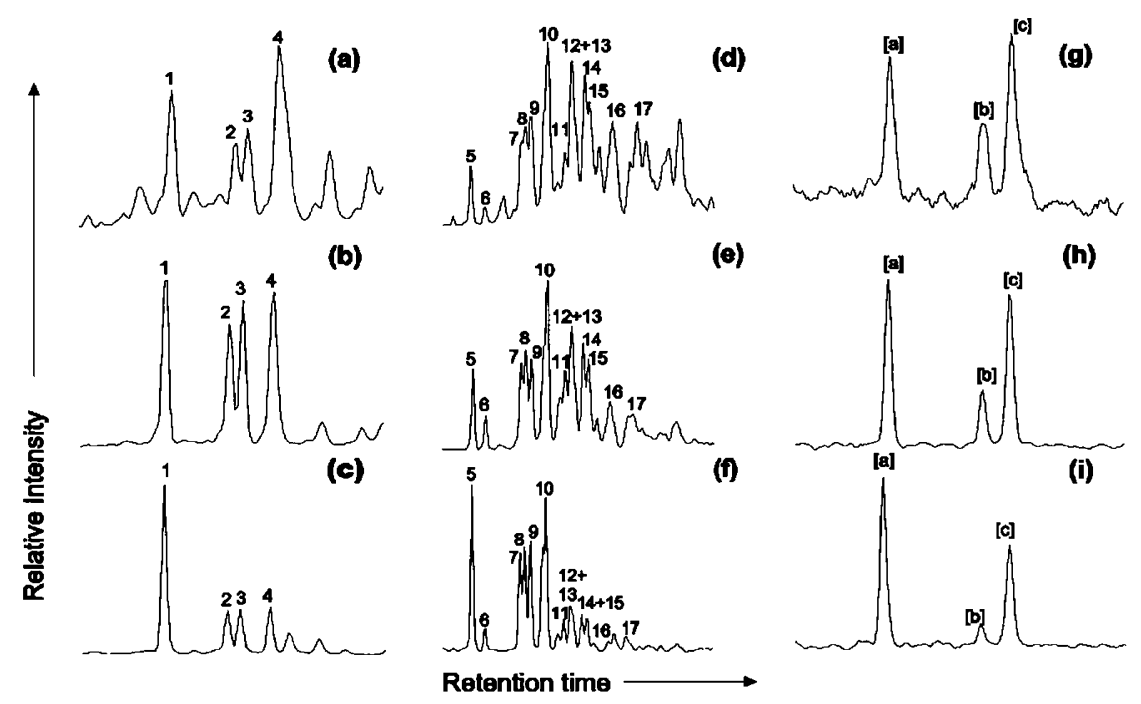

Fig. 1 Partial mass chromatograms representing (a, b and c) methylcarbazoles $(\mathrm{m} / \mathrm{z} 181)$, (d, e and f) $\mathrm{C}_{2}$-carbazoles $(\mathrm{m} / \mathrm{z}$ 195), and (g, h and i) benzocarbazole $(\mathrm{m} / \mathrm{z} 217)$ isomers $[a],[b]$ and $[c]$ isolated from Kimmeridge Clay hydropyrolysates, sample KC3 (upper traces, see Table 1) and sample KC4 (middle traces, see Table 1) and the Kimmeridge Clay Formation sourced Miller oil (lower traces). Key: $1=1$-methylcarbazole (MC), $\mathbf{2}=3$-MC, $\mathbf{3}=2$-MC, $\mathbf{4}=4$-MC; $\mathrm{C}_{2}$-carbazoles, $\mathbf{5}=1$ 1,8-dimethylcarbazole $(\mathrm{DMC}), \mathbf{6}=1$-ethylcarbazole, $\mathbf{7}=1,3$-DMC, $\mathbf{8}=1,6-\mathrm{MMC}$, $\mathbf{9}=1,7-\mathrm{DMC}, \mathbf{1 0}=1,4-\mathrm{DMC}+4$-ethylcarbazole $+1,5-\mathrm{DMC}+3$-ethylcarbazole, $\mathbf{1 1}=2,6-\mathrm{DMC}, \mathbf{1 2}=2,7-\mathrm{DMC}, \mathbf{1 3}=1,3-\mathrm{DMC}, \mathbf{1 4}=2,4-$ $\mathrm{DMC}, \mathbf{1 5}=2,5-\mathrm{DMC}, \mathbf{1 6}=2,3-\mathrm{DMC}, \mathbf{1 7}=3,4-\mathrm{DMC}$.

hydropyrolysates and oil are shown in Fig. 1, while the concentration data are listed in Table 2. In general, the hydropyrolysate from the bituminous mud (sample KC4) yielded significantly higher concentrations of alkylcarbazoles compared to the hydropyrolysate from the oil shale (sample KC3). Bakel and Philp ${ }^{14}$ found higher concentrations of organic nitrogen compounds in oils generated from phosphatic shales relative to carbonate source rocks during hydrous pyrolysis. Sample KC3 has a high carbonate content $(35 \%)$ compared to $\mathrm{KC} 4(1.7 \%)$ therefore finding lower amounts of alkylcarbazoles in sample $\mathrm{KC} 3$, although from hydropyrolysis in this case, is in agreement with the findings of Bakel and Philp. ${ }^{14}$ The results are also consistent with the differences found in alkylcarbazole distributions in organic extracts isolated from carbonate source rocks (Tithonian) compared to the clastic Posidoniaschiefer. ${ }^{21}$

The partial mass chromatograms $(m / z \quad 181)$ showing the distributions of methylcarbazoles isolated from the hydropyrolysates recovered from samples $\mathrm{KC} 3$ and $\mathrm{KC} 4$ are displayed in Fig. 1a and 1b, respectively. The dominant methylcarbazole in sample $\mathrm{KC} 3$ is 4-methylcarbazole, although a shoulder from a neighbouring unidentified compound, also with a $\mathrm{m} / \mathrm{z} 181$ ion may contribute to the peak (Fig. 1a). The 4 isomers of methylcarbazole (excluding 9-methylcarbazole) are present in similar relative abundance in sample KC4 (Fig. 1b). For comparative purposes, the methylcarbazole distribution obtained from a typical North Sea oil (from the Miller Field) is shown in Fig. 1c. A characteristic feature of the methylcarbazole distribution in the Miller oil is shown by the elevated relative abundance of 1-methylcarbazole compared to other methylcarbazole isomers (compare Fig. 1b and 1c).

The partial mass chromatograms $(\mathrm{m} / \mathrm{z}$ 195) showing distributions of the $\mathrm{C}_{2}$-alkylcarbazoles are displayed in Fig. 1d and 1efor the hydropyrolysates. Identification of individual isomers was made by comparison with the assignments published in Bowler et al. ${ }^{26}$ Dramatic relative abundance variations amongst the $\mathrm{C}_{2}$-alkylcarbazole isomers in the $\mathrm{m} / \mathrm{z}$ 195 mass chromatogram are seen between the hydropyrolysates (Fig. 1d and 1e) and the Miller oil (Fig. 1f). In general, the hydropyrolysates show reduced contributions from 1,8dimethylcarbazole, with significant increase in contributions from the peaks labelled 11-17 (Fig. 1d and 1e), while the converse is found in Miller oil (Fig. 1f). The peaks labelled 1117 in the $\mathrm{m} / z 195$ mass chromatograms (e.g., Fig. 1e), represent alkylcarbazole isomers (except 1,2-dimethylcarbazole, peak 13) where the nitrogen functionality is "exposed" due to absence of alkyl substituents in positions C-1 and C-8 (i.e. adjacent to the nitrogen functionality) e.g., 2,7-(12) and 3,4-(17) dimethylcarbazole. Therefore hydropyrolysis of immature $\mathrm{KCF}$ has generated alkylcarbazole distributions with significant contributions of the "exposed" isomers, relative to a typical KCFgenerated oil.

Although pyrolytically generated, the relative content of "shielded" $\mathrm{C}_{2}$-alkylcarbazole isomers to "exposed" isomers distributions of alkylcarbazoles in hydropyrolysates reveals similar features to alkylcarbazole distributions described in source rocks. ${ }^{19}$ The alkylcarbazole distributions generated during hydropyrolysis may provide an indication of the isomeric distributions present in source rocks prior to the processes associated with continuing source maturation.

\section{Benzocarbazoles}

The partial mass chromatograms $(m / z 217)$ representing the distribution of benzocarbazoles are displayed in Fig. 1g and $1 \mathrm{~h}$

Table 2 Concentrations ( $\mu \mathrm{g} \mathrm{g}^{-1}$ pyrolysate or oil) of alkylcarbazoles, benzocarbazoles and alkylindoles in hydropyrolysates generated from solvent extracted Kimmeridge Clay Formation (samples KC3 and KC4) and Miller Field (North Sea) production oil

\begin{tabular}{|c|c|c|c|c|c|c|c|c|c|c|c|}
\hline \multirow{2}{*}{ Sample } & \multicolumn{3}{|c|}{ Alkylcarbazoles } & \multicolumn{7}{|c|}{ Benzocarbazoles } & \multirow{2}{*}{$\begin{array}{l}\text { Alkylindoles } \\
\mathrm{C}_{2} \text {-indoles }\end{array}$} \\
\hline & Carbazole & $\mathrm{C}_{1}$-carbazoles & $\mathrm{C}_{2}$-carbazoles & [a] & {$[\mathrm{b}]$} & {$[\mathrm{c}]$} & {$[\mathrm{b}][\mathrm{a}]+[\mathrm{c}]$} & {$[\mathrm{a}][\mathrm{a}]+[\mathrm{c}]$} & Indole & $\mathrm{C}_{1}$-indoles & \\
\hline $\mathrm{KC} 3$ & 19.3 & 65.3 & 91.8 & 2.9 & 1.8 & 4.5 & 0.24 & 0.39 & 40.4 & 121.7 & 131.4 \\
\hline $\mathrm{KC4}$ & 227.9 & 358.1 & 321.4 & 20.7 & 8.0 & 19.4 & 0.20 & 0.52 & 21.0 & 127.6 & 284.6 \\
\hline Miller Oil & 7.6 & 29.6 & 70.2 & 2.8 & 0.4 & 1.9 & 0.09 & 0.60 & - & - & - \\
\hline
\end{tabular}


for the hydropyrolysates. Coinjection studies performed with sample $\mathrm{KC} 3$ and authentic standards of benzocarbazoles led to the assignments of benzo[a]- (IV), benzo[b]- (V) and benzo[c]carbazoles (VI). The hydropyrolysate from sample KC4 contained just over $5 \times$ more benzocarbazoles than sample KC3 (see Table 2). The interesting feature of the $\mathrm{m} / \mathrm{z} 217$ mass chromatograms (Figs. $1 \mathrm{~g}$ and $1 \mathrm{~h}$ ) of the hydropyrolysates compared to the oil (Fig. 1i) is the enhancement of benzo[b]carbazole relative to benzo $[a]$ carbazole and benzo $[c]$ carbazole also confirmed by the ratio of benzo[b]carbazole to both benzo $[a]-$ and benzo $[a]$ carbazole isomers abbreviated to $[b] /$ $([a]+[c])$ (Table 2). Based on the literature, there are 4 possible processes which may give rise to an enhancement of benzo $[b]$ carbazole relative to benzo $[a]$ carbazole and benzo $[c]-$ carbazole:

(i) Indicators of terrestrial contribution: in general, ben$\mathrm{zo}[a]$ carbazole and benzo $[c]$ carbazole are predominant in rock extracts and crude oils from clastic and carbonate marine source systems, whereas benzo[b]carbazole is either absent or occurs in relatively minor abundances. ${ }^{20,21}$ Harrison et al. ${ }^{27}$ reported increased contributions of the benzo[b]carbazole isomer relative to $[a]$ and $[c]$ isomers in Carboniferous coals of northwestern Europe, therefore, benzo[b]carbazole may indicate a terrestrial (coal derived) contribution to source organic matter.

(ii) Pyrolysis products: unusually high levels of benzocarbazoles, in particular high abundance of benzo[ $b]$ carbazole were identified in produced oils from the Jedburgh well (Canadian Williston basin). The oils were thought to be generated by high temperature, short-term pyrolysis of thermally immature organic matter. ${ }^{28}$ In this case, the high abundance of benzo $[b]$ carbazole is concurrent with the high abundance of aromatic hydrocarbons with a linear structure relative to the angularly condensed structures, as indicated by high anthracene to phenanthrene ratio. Appreciable quantities of all benzocarbazole isomers and enhanced contributions from the benzo $[b]$ carbazole were identified in hydropyrolysates from KCF during this study.

(iii) Thermodynamic relative stability: calculation using the semi-empirical PM3-method (Adri van Duin, pers comm) produces the heats of formation for the following compounds: benzo[a]carbazole, $\quad 70.71 \mathrm{kcal} \mathrm{mol}^{-1}$; benzo $[b]$ carbazole, $71.21 \mathrm{kcal} \mathrm{mol}^{-1}$; and benzo[c]carbazole, $69.93 \mathrm{kcal} \mathrm{mol}^{-1}$. Thus, benzo $[b]$ carbazole is defined as the least stable isomer of the benzocarbazoles. Since hydropyrolysis is a conservative technique which favours the release of products with retention of structural and stereochemical features, ${ }^{3}$ the increased yields of benzo[b]carbazoles in hydropyrolysates may be a consequence of the "soft" pyrolysis conditions.

(iv) Fractionation processes: the polar nature of benzocarbazoles enables strong interactions with minerals/organic matter through hydrogen bonding. The solubility parameters estimated for benzocarbazoles are similar at $24.9 \mathrm{MPa}^{1 / 2}$ indicating the strong affinity of benzocarbazoles to organic matter. ${ }^{20}$ The molecular shape also proved an important consideration during petroleum migration where the selective removal of the rod-shaped benzo[a]carbazole relative to the subspherical benzo $[c]$ carbazole. ${ }^{20}$ The benzo $[b]$ carbazole is a linearly fused aromatic structure, and therefore, in addition to hydrogen bonding interactions it may be amenable to a molecular sieving mechanism. As a consequence, benzo[b]carbazole may be selectively retained in the source rock and during petroleum expulsion may not be expelled as efficiently as benzo $[a]$ - and benzo $[c]$ carbazole. Similarly, both 1-methylcarbazole and 1,8-dimethylcarbazole ("shielded" isomers) are abundant isomers in the Miller oil, while the hydropyrolysates showed enhanced quantities of nitrogen "exposed" isomers compared to the "shielded" isomers. Therefore, using simple chromatographic theory, the preferential retention of nitrogen "exposed" isomers by the source rock may explain the different

distributions of benzocarbazoles (and alkylcarbazoles) in the hydropyrolysates and the Miller oil.

\section{Indoles}

The partial mass chromatograms of the molecular ions representing the distributions of $\mathrm{C}_{0}-\mathrm{C}_{2}$ alkylindoles $(\mathrm{m} / \mathrm{z} 117$, $131,145)$ are shown in Fig. 2. The main component in the $\mathrm{m} / \mathrm{z}$ 117 mass chromatogram (Fig. 2a and 2b) was assigned to indole (I) based on greater than $98 \%$ fit with mass spectra from the HP Chemstation mass spectra library (NIST 98). Coinjection studies with authentic 2-methylindole standard and sample $\mathrm{KC} 3$ indicated that the peak identified by the asterisk in the $\mathrm{m} / \mathrm{z}$ 131 mass chromatogram (Fig. 2c) co-eluted with 2-methylindole. The concentrations of indole, methylindoles and $\mathrm{C}_{2}-$ alkylindoles were calculated (semi-quantitative) by comparing the areas from the major peaks ( $>20 \%$ relative peak height to the major intensity peak) in the $m / z 117,131$ and 145 molecular ion chromatograms relative to the peak area in the $\mathrm{m} / \mathrm{z} 243$ chromatogram representing $N$-phenylcarbazole standard (Table 2). The alkylindoles were present in quantities of a similar order of magnitude to the alkylcarbazoles and thus represent a significant contribution to the pyrrolic nitrogen compounds. Both samples KC3 and KC4 contain abundant indoles, with sample $\mathrm{KC} 3$ having enhanced indole concentrations compared to $\mathrm{C}_{2}$-alkylindoles, while in sample $\mathrm{KC4}$, the $\mathrm{C}_{2}$-indoles were relatively more abundant (Table 2).

Analysis of Miller oil failed to identify the presence of indoles. Since the indoles are known to be highly unstable, as exemplified by their ability to contribute to sediment formation in middle distillates and fuel oils ${ }^{18}$ their absence from Miller oil may be due to alteration at some stage prior to sample

KC3

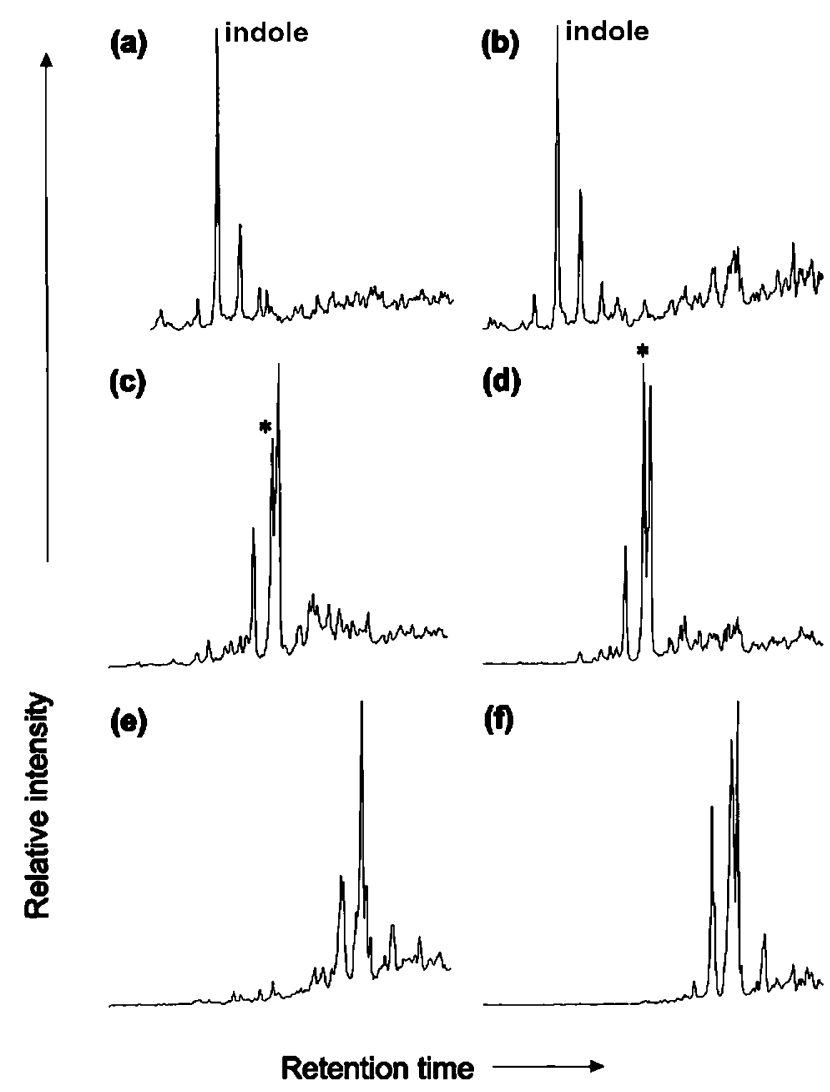

Fig. 2 Partial mass chromatograms (a) and (b) representing indole $(\mathrm{m} / \mathrm{z}$ $117)$, (c) and (d) methylindoles $(\mathrm{m} / \mathrm{z} 131)$, and (e) and (f) $\mathrm{C}_{2}$-alkylindoles $(\mathrm{m} / z$ 145) in C18 NEC SPE isolates from the hydropyrolysates generated from solvent extracted Kimmeridge Clay Formation (samples KC3 and KC4, see Table 1) (2-methylindole indicated by *). 
(a) Quinoline

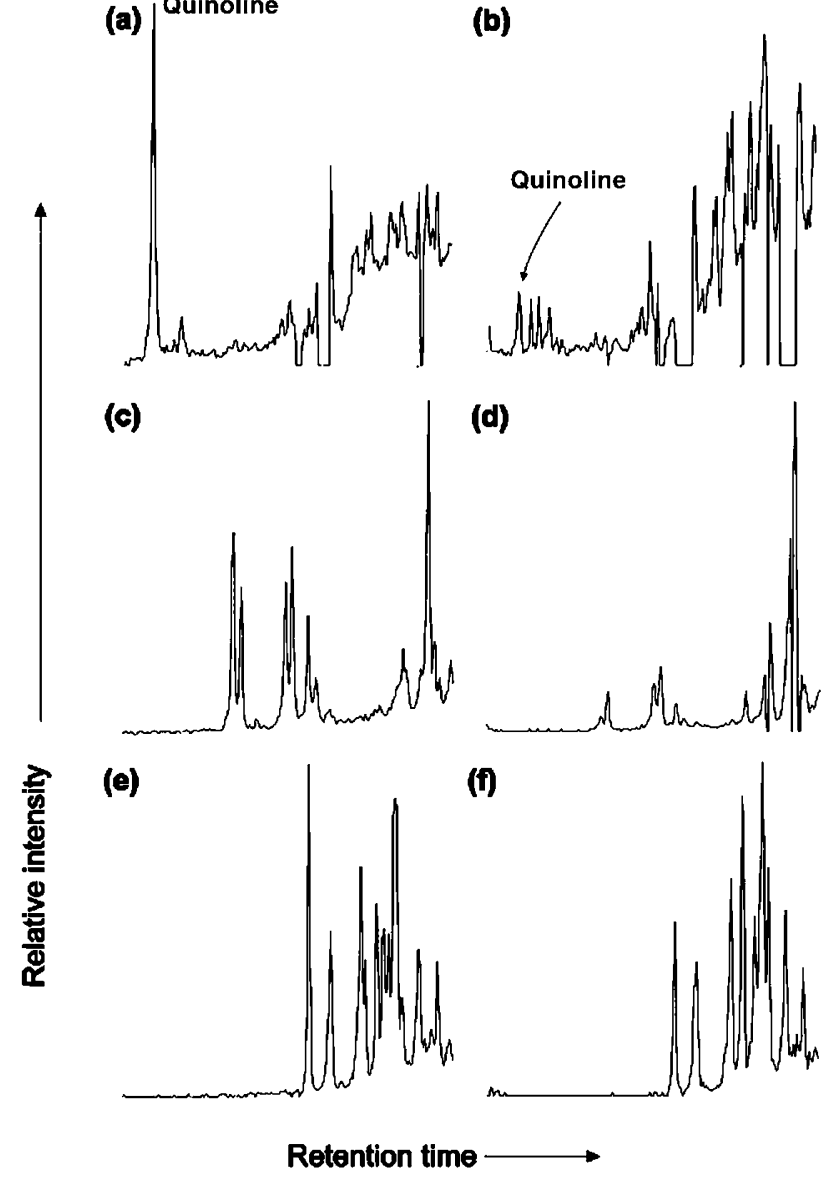

Fig. 3 Partial mass chromatograms (a) and (b) representing quinoline ( $m / z$ 129), (c) and (d) methylquinolines ( $m / z 143$ ), and (e) and (f) $\mathrm{C}_{2^{-}}$ alkylquinolines $(\mathrm{m} / \mathrm{z} 157)$ in polar non-hydrocarbon fractions isolated using C18 NEC SPE from the hydropyrolysates generated from solvent extracted Kimmeridge Clay Formation (samples KC3 and $\mathrm{KC} 4$, see Table 1).

preparation, in the subsurface and/or during sampling and storage. However, it appears that the indoles are more commonly associated with pyrolysis products and shale oil processing. Significant quantities of indoles have been identified in retorted Condor oil shale and Green River oils ${ }^{29}$ and $700-850{ }^{\circ} \mathrm{F}$ distillate from a Californian crude oil. ${ }^{30}$ The alkylindole content of the hydropyrolysates represents a major component of the pyrrolic nitrogen species present in kerogen, and although not identified in Miller oil, the indoles represent a potential source of aromatic nitrogen species ultimately contributing to the nitrogen compounds formed during burial or on catagenetic release from the source rock.

\section{Nitrogen bases}

The partial mass chromatograms $(m / z 129,143,157)$ showing the distributions of $\mathrm{C}_{0}-\mathrm{C}_{2}$-alkylquinolines in the hydropyrolysates from samples $\mathrm{KC} 3$ and $\mathrm{KC} 4$ are displayed in Fig. 3. Quinoline (VIII) (indicated in Fig. 3a) was tentatively identified from its mass spectrum, GC retention behaviour and cochromatography with respect to the authentic standard. Quinoline and its alkyl homologues could not be identified in Miller oil. In contrast, Schmitter et al. ${ }^{13}$ identified quinoline compounds with alkylation extending up to $\mathrm{C}_{9}$ (maximum $\mathrm{C}_{6}$ ) in 9 petroleum samples from California, although the unsubstituted parent compound was absent.

The benzoquinoline distributions are inherently complex since the parent molecule can be found as one of eight isomers based on the arrangement of the benzene rings (e.g.

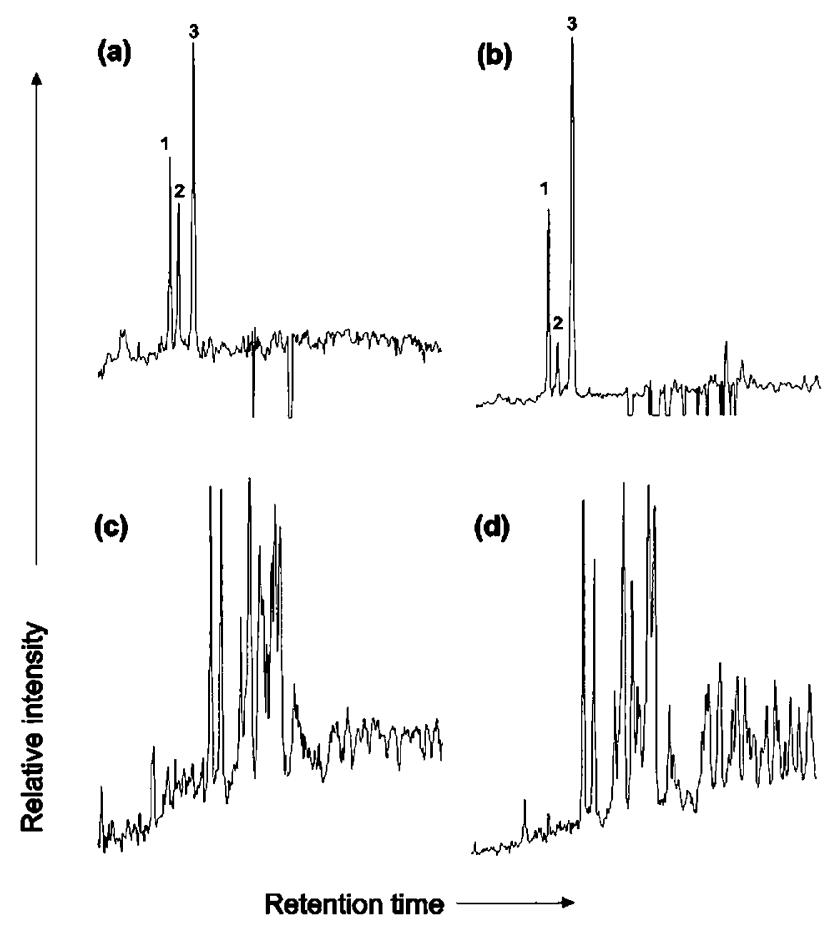

Fig. 4 Partial mass chromatograms (a) and (b) representing benzoquinolines $(\mathrm{m} / \mathrm{z} 179)$ and (c) and (d) representing methylbenzoquinolines $(\mathrm{m} / \mathrm{z}$ 193) in polar non-hydrocarbon fractions isolated from the hydropyrolysates generated from solvent extracted Kimmeridge Clay Formation (samples $\mathrm{KC} 3$ and KC4, see Table 1) using C18 NEC SPE. Key: $\mathbf{1}=$ benzo $[h]$ quinoline $(\mathbf{I X}), \mathbf{2}=$ acridine $(\mathbf{X}), \mathbf{3}=$ benzo[f]quinoline (XI) + phenanthridine (XII).

benzo $[h]$ quinoline (IX) $v$ s. acridine $(\mathbf{X})$ ) and location of the nitrogen group in the aromatic ring system (e.g., benzo[flquinoline (XI) vs. phenanthridine (XII)). The partial mass chromatograms $(\mathrm{m} / \mathrm{z} 179,193)$ showing the distributions of benzoquinolines and methylbenzoquinolines from the hydropyrolysates are displayed in Fig. 4. The partial mass chromatogram $(\mathrm{m} / \mathrm{z}$ 179) representing benzoquinolines displays 3 major peaks (Figs. $4 \mathrm{a}$ and $4 \mathrm{~b}$ ). Co-injection studies carried out with the authentic standards and the hydropyrolysate from $\mathrm{KC} 3$ indicated that benzo $[h]$ quinoline (IX) and acridine (X) coeluted with peaks 1 and 2, respectively. However, under the GC conditions employed at least 2 components (benzo[f]quinoline (XI) and phenanthridine (XII)) co-eluted with peak 3 , indicated in Fig. $4 \mathrm{a}$ and $4 \mathrm{~b}$. The $\mathrm{C}_{0}-\mathrm{C}_{1}$ alkylbenzoquinolines were absent from Miller oil.

The partial mass chromatograms $(m / z$ 207) showing the distributions of $\mathrm{C}_{2}$-alkylbenzoquinolines in the hydropyrolysates are shown in Fig. 5a and 5b. For comparison, the $\mathrm{m} / z 207$ mass chromatogram from Miller oil is shown in Fig. 5c. The distribution of $\mathrm{C}_{2}$-alkylbenzoquinoline in Miller oil is characterised by the dominance of a single component (labelled $\mathrm{S}$ in Fig. 5c). The $\mathrm{C}_{2}$-alkylbenzoquinolines distribution in Miller oil revealed by the $\mathrm{m} / \mathrm{z} 207$ mass chromatogram is similar to the $\mathrm{C}_{2}$-alkylbenzoquinoline distributions obtained from a Sarukawa oil (SA 12) presented by Yamamoto. ${ }^{23}$ The structure and position of alkyl groups relative to the nitrogen group is known to affect the $\mathrm{GC}$ retention behaviour of $\mathrm{C}_{2}$-alkylbenzoquinolines. The nitrogen "shielded" (short GC retention times) isomers elute more readily than nitrogen "exposed" (long retention times) isomers. Therefore, using GC retention orders (short retention times vs. long retention times), Yamamoto et $a l .{ }^{12}$ compared the distributions of $\mathrm{C}_{2}$-alkylbenzoquinolines between bitumens and crude oils. The profiles shown by the $\mathrm{C}_{2}-$ alkylbenzoquinolines eluting at shorter retention times were 


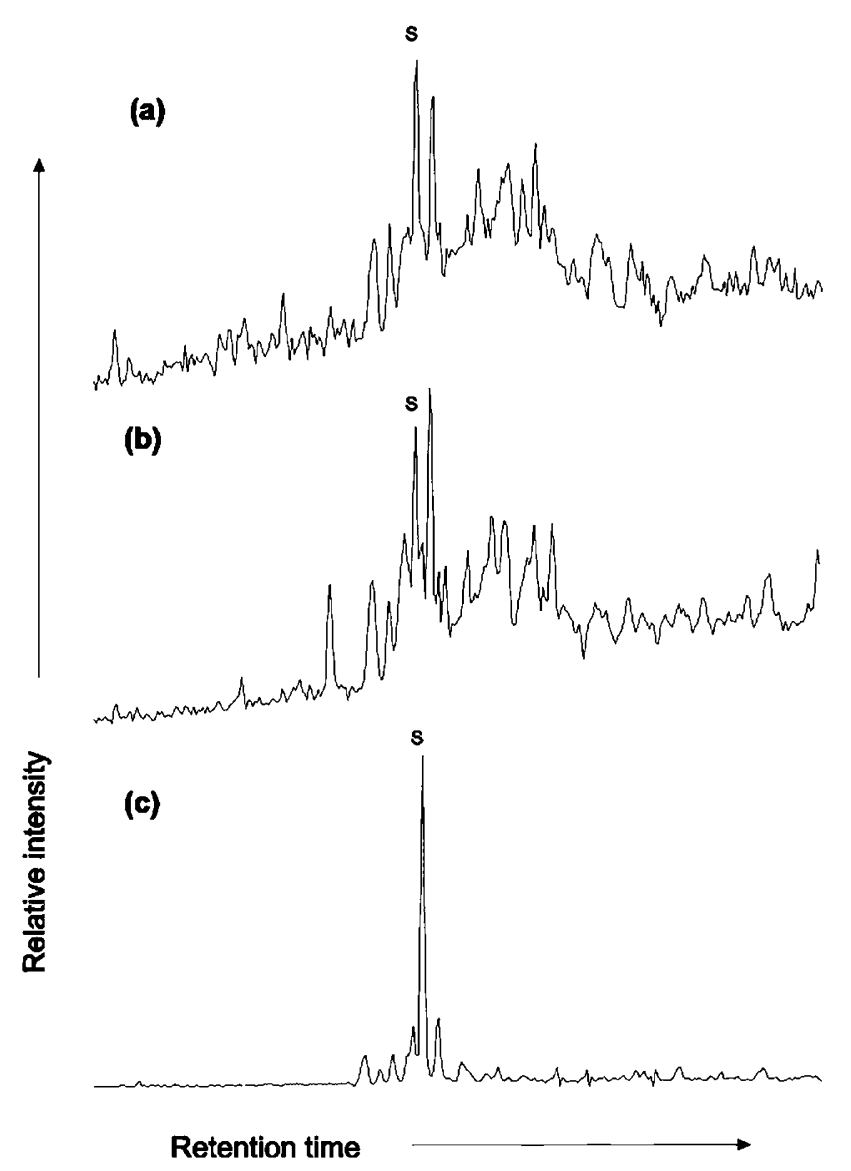

Fig. 5 Partial mass chromatograms representing the $\mathrm{C}_{2}$-alkylbenzoquinolines $(\mathrm{m} / \mathrm{z} 207)$ in polar non-hydrocarbon fractions isolated by C18 NEC SPE of the hydropyrolysate samples (a) KC3 and (b) KC4 (see Table 1) and (c) Miller oil. Key: $\mathrm{S}=$ shielded isomer(s).

similar in both source rock bitumen and crude oils; however, isomers with longer retention times present in the source rocks, were absent from crude oils. ${ }^{12}$ The distribution of alkylbenzoquinoline isomers between organic extracts of source rocks and related crude oils was suggested as evidence for fractionation of nitrogen compounds during petroleum migration. The $\mathrm{C}_{2}-$ alkylbenzoquinolines in Miller oil (Fig. 5c) compared to the complex distribution of the hydropyrolysates (e.g., Fig. 5a) may indicate the preferential accumulation of nitrogen shielded isomers of $\mathrm{C}_{2}$-benzoquinoline during petroleum migration (see Fig. 5).

\section{Conclusions}

(i) Hydropyrolysis of solvent-extracted Kimmeridge Clay Formation shales released significant quantities of nitrogen compounds including carbazoles, benzocarbazoles, quinolines, benzoquinolines and indoles.

(ii) Comparable amounts of both "shielded" and "exposed" isomers in the methyl- and $\mathrm{C}_{2}$-alkylcarbazoles as well as increased abundance of benzo[b]carbazole relative to benzo $[a]-$ and benzo[c]carbazole typify the hydropyrolysates compared to a North Sea oil.

(iii) The indoles represent a major component of the nitrogen compounds in immature kerogen and through cyclisation and aromatisation of alkylindoles during further maturation, it may be possible to generate carbazoles.

(iv) The production of vast quantities of carbazoles and benzocarbazoles from the immature $\left(0.35 \% R_{\mathrm{o}}\right) \mathrm{KCF}$ indicate that aromatic heterocyclic nitrogen compounds are formed at a relatively early stage of diagenesis.

(v) The nitrogen compounds produced during hydropyr- olysis of the KCF provide a means to indicate the mass balance of nitrogen compounds through providing an initial nitrogen compound distribution prior to effects of primary migration, expulsion and secondary migration.

\section{Acknowledgements}

The authors acknowledge Prof. Colin E. Snape and the University of Strathclyde for use of the high pressure hydrogen pyrolysis rig. The POLARIS consortium (Exxon, Shell, Statoil and Texaco) is also thanked for funding. We thank Paul Donohoe and Kim Noke for performing GC-MS, Jane Barnard for providing Kimmeridge Clay samples and Prof. Steve Larter and Dr. Adri van Duin for useful discussions. Andrew Fleet (B.P.) is thanked for kindly donating the Miller platform crude oil.

\section{References}

1 C. J. Lafferty, S. C. Mitchell, R. Garcia and C. E. Snape, Investigation of organic sulfur forms in coals by high temperatureprogrammed reduction, Fuel, 1993, 72, 367.

2 M. J. Roberts, C. E. Snape and S. C. Mitchell, in Geochemistry, Characterisation and Conversion of Oil Shales, ed. C. E. Snape, Kluwer, Dordecht, 1995, NATO ASI Series C, vol. 455, pp. 277295.

3 G. D. Love, C. E. Snape, A. D. Carr and R. C. Houghton, Release of covalently-bound biomarkers in high yields from kerogen via catalytic hydropyrolysis, Org. Geochem., 1995, 23, 981.

4 G. D. Love, C. E. Snape, A. D. Carr and R. C. Houghton, Changes in molecular biomarker and bulk carbon skeletal parameters of vitrinite concentrates as a function of rank, Energy Fuels, 1996, 10, 149.

5 G. D. Love, A. McAulay, C. E. Snape and A. N. Bishop, Effect of process variables in catalytic hydropyrolysis on the release of covalently-bound aliphatic hydrocarbons from sedimentary organic matter, Energy Fuels, 1997, 11, 522.

6 G. D. Love, C. E. Snape and A. E. Fallick, Differences in the mode of incorporation and biogenicity of the principal aliphatic constituents of a Type I oil shale, Org. Geochem., 1998, 281, 797.

7 A. N. Bishop, G. D. Love, C. E. Snape and P. Farrimond, Release of kerogen-bound hopanoids by hydropyrolysis, Org. Geochem., 1998, 29, 989.

8 I. P. Murray, G. D. Love, C. E. Snape and N. J. L. Bailey, Comparison of covalently-bound aliphatic biomarkers released via hydropyrolysis with their solvent-extractable counterparts for a suite of Kimmeridge clays, Org. Geochem., 1998, 29, 1487.

9 I. P. Murray, C. E. Snape, G. D. Love and N. J. L. Bailey, Hydropyrolysis of heavy oil fractions for source correlation studies, Proc. 19th International Meeting on Organic Geochemistry, 1999, Abstracts Part I, pp. 341-342, Istanbul, Sept. 1999.

10 L. F. Thompson and S. A. Holmes, Effect of multistage hydroprocessing on aromatic and nitrogen compositions of shale oil, Fuel, 1985, 64, 9.

11 B. R. Simoneit, H. K. Schones, P. Haug and A. L. Burlingame, High resolution mass spectrometry of nitrogenous compounds of the Colorado Green River formation oil shale, Chem. Geol., 1971, 7, 123.

12 M. Yamamoto, T. Taguchi and K. Sasaki, Basic nitrogen compounds in bitumen and crude oils, Chem. Geol., 1991, 93, 193.

13 J. M. Schmitter, I. Ignatiadas and P. J. Arpino, Distribution of diaromatic nitrogen bases in crude oils, Geochim. Cosmochim. Acta, 1983, 47, 1975.

14 A. J. Bakel and R. P. Philp, The distribution and quantitation of organonitrogen compounds in crude oils and rock pyrolysates, Org. Geochem., 1990, 16(1-3), 353.

15 F. P. Richter, P. D. Caeser, S. L. Meisel and R. D. Offenhauer, Distribution of nitrogen in petroleum according to basicity, Ind. Eng. Chem., 1952, 44, 2601.

16 L. R. Snyder, Petroleum nitrogen compounds and oxygen compounds, Acc. Chem. Res., 1970, 3, 290.

17 M. Dorbon, J. M. Schmitter, P. Garrigues, I. Ignatiadis, M Edward, P. Arpino and G. Guichon, Distribution of carbazole derivatives in petroleum, Org. Geochem., 1984, 7, 111

18 J. H. Wynne, W. M. Stalick and G. W. Mushrush, Fuel instability studies: The synthesis of long chain alkyl substituted indoles, Pet. Sci. Technol., 2000, 18(1-2), 221. 
19 M. Li, S. R. Larter, D. P. Stoddart and M. Bjoroy, in Fractionation of pyrrolic nitrogen compounds in petroleum during reservoir filling: derivation of migration related geochemical parameters, ed. W. A. England and J. Cubitt, Reservoir Geochemistry, Geological Society, Special Publication, 1995.

20 S. R. Larter, B. F. J. Bowler, M. Li, M. Chen, D. Brincat, B. Bennett, K. Noke, P. Donohoe, D. Simmons, M. Kohnen, J. Allan, N. Telnaes and I. Horstad, Molecular indicators of secondary oil migration distances, Nature, 1996, 383, 593.

21 B. Horsfield, H. Clegg, H. Wilkes and D. Santamaria-Orozco, Effect of maturity on carbazole distributions in petroleum systems: New insights from the Sonda de Campeche, Mexico, and Hils Syncline, Germany, Naturwissenschaften, 1998, 85, 233 .

22 L. R. Snyder and B. E. Buell, Nitrogen and oxygen compound types in petroleum: A general separation scheme, Anal. Chem., 1968, 40(8), 1295

23 M. Yamamoto, Fractionation of azarenes during oil migration, Org. Geochem., 1992, 19, 389.

24 L. Brothers, M. H. Engel and B. M. Kroos, The effects of fluid flow through porous media on the distribution of organic compounds in a synthetic crude oil, Org Geochem., 1991, 17, 11.

25 B. Bennett, B. F. J. Bowler and S. R. Larter, Rapid methods for determination of $\mathrm{C}_{0}-\mathrm{C}_{2}$ alkylphenols in crude oils and waters, Anal. Chem., 1996, 68, 3697.

26 B. F. J. Bowler, S. R. Larter, H. Clegg, H. Wilkes, B. Horsfield and M. Li, Dimethylcarbazoles in crude oils: Comment on liquid chromatographic separation schemes for pyrrole and pyridine nitrogen aromatic heterocyclic fractions from crude oils suitable for rapid characterization of geochemical samples, Anal. Chem. 1997, 69, 15, 3128.

27 E. Harrison, N. Telnaes, A. Wilhelms, B. Horsfield, A. van Duin, B. Bennett and S. R. Larter, in Proc. 18th International Meeting on Organic Geochemistry, Maastricht, The Netherlands, 22-26 September 1997, Abstracts Part I, pp. 235-236.

28 M. Li, K. G. Osadetz, H. Yao, M. Obermajer, M. G. Fowler, L. R. Snowdon and R. Christensen, Unusual crude oils in the Canadian Williston Basin, southeastern Saaskatchewan, Org. Geochem., 1998, 28, 477.

29 C. E. Rovere, P. T. Crisp, J. Ellis and J. Korth, Chemical class separation of shale oils by low pressure liquid chromatography on thermally-modified adsorbants, Fuel, 1990, 69, 1099.

30 L. R. Snyder, B. E. Buell and H. E. Howard, Nitrogen and oxygen compound types in petroleum: Total analysis of a 700 $850{ }^{\circ} \mathrm{F}$ distillate from a California crude oil, Anal. Chem., 1968 40(8), 1303. 